\title{
Effect of Aging Treatment on Precipitation Behavior and Mechanical Properties of a Novel Aluminum-Lithium Alloy
}

\author{
Hua-Guan Li · Juan Ling • Yi-Wei Xu • Zhong-Gang Sun • \\ Hong-Bing Liu $\cdot$ Xing-Wei Zheng $\cdot$ Jie Tao
}

Received: 11 October 2014/Revised: 29 December 2014/Published online: 5 March 2015

(C) The Chinese Society for Metals and Springer-Verlag Berlin Heidelberg 2015

\begin{abstract}
In this work, the microstructure and precipitation phases were primarily characterized by transmission electron microscopy. The mechanical properties were evaluated by tensile and tear test. The results indicated that the samples aged at $145{ }^{\circ} \mathrm{C}$ for $45 \mathrm{~h}$ or $155^{\circ} \mathrm{C}$ for $30 \mathrm{~h}$ possessed a preferable combination of strength and plasticity, owing to the precipitation of well-dispersed $\mathrm{T}_{1}\left(\mathrm{Al}_{2} \mathrm{CuLi}\right)$ phases (diameter $<150 \mathrm{~nm}$ ). However, aging at more than $165{ }^{\circ} \mathrm{C}$ caused an obvious size growth of $\mathrm{T}_{1}$ plates, leading to the quick reduction in plasticity and toughness. Furthermore, the high $\mathrm{Cu} / \mathrm{Li}$ ratio resulted in distinct precipitation features, including a shorter incubation time of $\mathrm{T}_{1}$ phase and the aggravated precipitate-free zones.
\end{abstract}

KEY WORDS: Aluminum-lithium alloy; Aging treatment; Fracture toughness; Microstructure

\section{Introduction}

The aluminum-lithium alloys have attractive applications in the aerospace industry owing to their lower density, better strength and higher stiffness comparing to the conventionally commercial $2 \mathrm{xxx}$ and $7 \mathrm{xxx}$ series aluminum alloys [1]. However, their applications are still limited by insufficient plasticity, toughness and obvious anisotropy [2]. As it is known, the aging treatment is a crucial technology for the aluminum-lithium alloys to improve

Available online at http://link.springer.com/journal/40195

H.-G. Li · J. Ling · Y.-W. Xu · J. Tao $(\bowtie)$

College of Material Science and Technology, Nanjing University

of Aeronautics and Astronautics, Nanjing 211100, China

e-mail: taojie@nuaa.edu.cn

H.-G. Li · J. Tao

Jiangsu Key Laboratory of Advanced Structural Materials and Application Technology, Nanjing 211100, China

Z.-G. Sun · H.-B. Liu $\cdot$ X.-W. Zheng

Shanghai Aircraft Manufacturing Company Limited, Shanghai 200436, China strength, plasticity and toughness [3, 4]. Among the aging treatments, single aging shows the highest efficiency $[5,6]$.

At present, the processing of the aluminum-lithium alloys is treated as the key technology, as Chinese are devoting ourselves to develop the commercial aircraft. Generally, the aluminum-lithium alloys are formed firstly in the annealed or as-quenched condition. And then, aging treatment is applied to strengthen the alloy, which process is extremely important in the requirement of aircraft damage tolerance. The solution-aging treatment of $\mathrm{Al}-\mathrm{Cu}-\mathrm{Li}$ family was investigated in last decade, and some precipitation behaviors have been explored [7]. However, the ternary system $\mathrm{Al}-\mathrm{Cu}-$ Li evidences a complex precipitation sequence [8]. These alloys possess $\delta^{\prime}\left(\mathrm{Al}_{3} \mathrm{Li}\right), \mathrm{T}_{1}\left(\mathrm{Al}_{2} \mathrm{CuLi}\right), \theta^{\prime}\left(\mathrm{Al}_{2} \mathrm{Cu}\right)$, as well as their composite phases, and have even greater diversity of the precipitates after the addition of minor elements such as $\mathrm{Mg}$ and $\mathrm{Ag}$ [9]. Furthermore, it is worth mentioning that the $\mathrm{Cu} /$ $\mathrm{Li}$ ratio greatly influences the precipitation behavior of $\mathrm{Al}-$ $\mathrm{Cu}-\mathrm{Li}$ alloy [10]. Decreus et al. [11] have analyzed the effect of the $\mathrm{Cu} / \mathrm{Li}$ ratio ranging from 1.7 to 3.4 on the sequence and kinetics of precipitation. The Li-rich alloy showed a much longer incubation time and a larger saturation diameter of $\mathrm{T}_{1}$ plates than the Li-poor alloy. It was also proved that the 
existence of $\mathrm{Li}$ was able to retard the growing and coarsening of the precipitates in high-strength aluminum alloys [12]. As a novel member of aluminum-lithium family, the investigated alloy has a higher $\mathrm{Cu} / \mathrm{Li}$ ratio to 5.29 , which makes it necessary to explore the effect of the aging parameters on the precipitation behavior and mechanical properties.

Besides, the formation of precipitate-free zones (PFZ) [13], which is believed to affect greatly the mechanical properties of aluminum alloys [14], requires much attention during aging treatment. The recent studies [15] have revealed that the presence of PFZ adversely affects the fracture properties of the alloys by correlating mechanical properties to microstructure. During the aging treatment of the novel aluminum-lithium alloys, the investigation on the formation and aggravation of PFZ is quite valuable.

Finally, it is essential to measure the fracture toughness of aluminum-lithium sheet during the aging process, which is regarded as an important part of damage tolerance [16, 17]. At present, tear test [18], based on the resistance of the material to tearing, is an established test for ranking damage tolerance and can be correlated with plain stress fracture toughness. In this study, the tear test was adopted to measure fracture toughness of the novel alloy.

Table 1 Chemical composition of the novel aluminum-lithium alloy (wt $\%)$

\begin{tabular}{llllllll}
\hline $\mathrm{Li}$ & $\mathrm{Cu}$ & $\mathrm{Mg}$ & $\mathrm{Ag}$ & $\mathrm{Zr}$ & $\mathrm{Mn}$ & $\mathrm{Zn}$ & $\mathrm{Al}$ \\
\hline 0.7 & 3.7 & 0.7 & 0.34 & 0.11 & 0.29 & 0.32 & Bal. \\
\hline
\end{tabular}

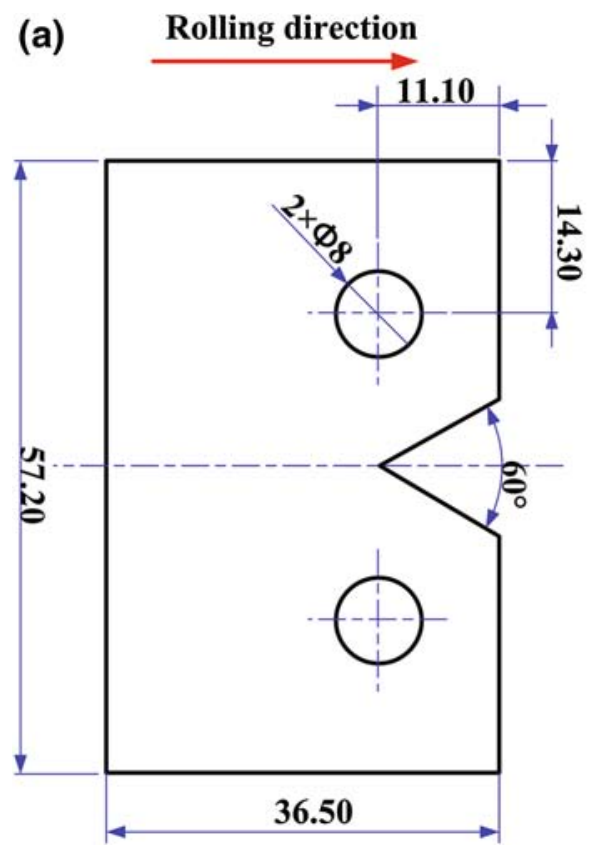

\section{Experimental}

The chemical composition of the novel aluminum-lithium alloy sheets ( $2 \mathrm{~mm}$ thickness) is given in Table 1 . The solution treatment was conducted at $525^{\circ} \mathrm{C}$ for $30 \mathrm{~min}$. A KU-15-06-A air circulating furnace was used in this process to ensure the accuracy and uniformity of temperature (within $\pm 1{ }^{\circ} \mathrm{C}$ ). Then, the alloy was water quenched at room temperature. The aging treatment was conducted in the thermostatic drying chamber with temperature uniformity within $\pm 0.5^{\circ} \mathrm{C}$, and the left samples after quenching were kept in a refrigerated condition $\left(<-20{ }^{\circ} \mathrm{C}\right)$ to avoid natural aging effect.

The tensile properties were investigated according to the ASTM E8/E 8 M-08, taking the specimens perpendicular to the rolling direction. MTS 370 testing machine was applied at a displacement rate of $2 \mathrm{~mm} / \mathrm{min}$. Meanwhile, the tear test was performed to evaluate the toughness of the novel alloy, where the crack propagated along the rolling direction in the $\mathrm{C}(\mathrm{T})$ specimen (Fig. 1a). A displacement rate of $2 \mathrm{~mm} / \mathrm{min}$ was adopted in a CMT-5105 testing machine referring to ASTM B871, and the objective graph is shown in Fig. 1b. The tests gave two measures of toughness: the ultimate propagation energy $\left(E_{\mathrm{UP}}\right)$ and the ratio of the tear strength to the yield strength $\left(R_{\mathrm{TY}}\right)$ [19].

Samples of the aged alloy for transmission electron microscopy (TEM) observation were prepared to investigate the precipitation behavior. Firstly, the slices with a thickness of $100 \mu \mathrm{m}$ were obtained by chemical etching in $20 \%$ sodium hydroxide solution. Secondly, the samples for TEM were

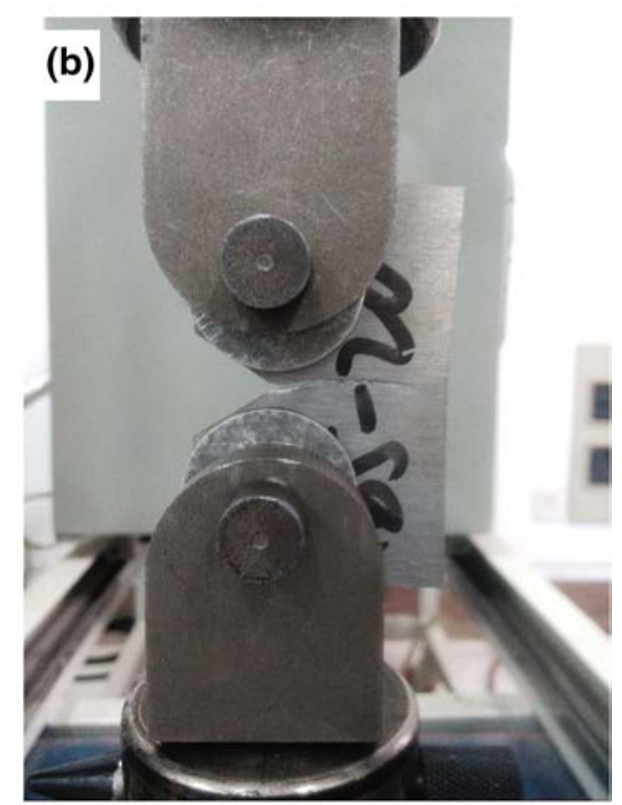

Fig. 1 The tear test of the novel aluminum-lithium alloy: a the specimen geometries (in $\mathrm{mm}$ ); $\mathbf{b}$ the objective graph 
prepared by electro-polishing in a twin-jet apparatus, using a $30 \%$ nitric acid-methanol solution at $-20^{\circ} \mathrm{C}$ under $15 \mathrm{~V}$. Finally, TEM observation was performed on a FEI-TECNAI $\mathrm{G}^{2}$ transmission electron microscope operated at $200 \mathrm{kV}$.

\section{Results and Discussion}

\subsection{Mechanical Properties}

The tensile properties of the novel aluminum-lithium alloy are shown in Fig. 2. The tensile strength raises, and the plasticity deteriorates with the increasing aging temperature and time. The investigated alloy reaches the peakaging state after a treatment at $165^{\circ} \mathrm{C}$ for $20 \mathrm{~h}$. But if we decrease the temperature to $145^{\circ} \mathrm{C}$, a longer aging time with $45 \mathrm{~h}$ was needed to obtain the peak strength. Moreover, when reaching the peak-aging state, the novel alloy exhibits the elongation of $7.30 \%$ at $165^{\circ} \mathrm{C}$ for $20 \mathrm{~h}$, while $11.51 \%$ at $145{ }^{\circ} \mathrm{C}$ for $45 \mathrm{~h}$, shown in Fig. 2c. These results

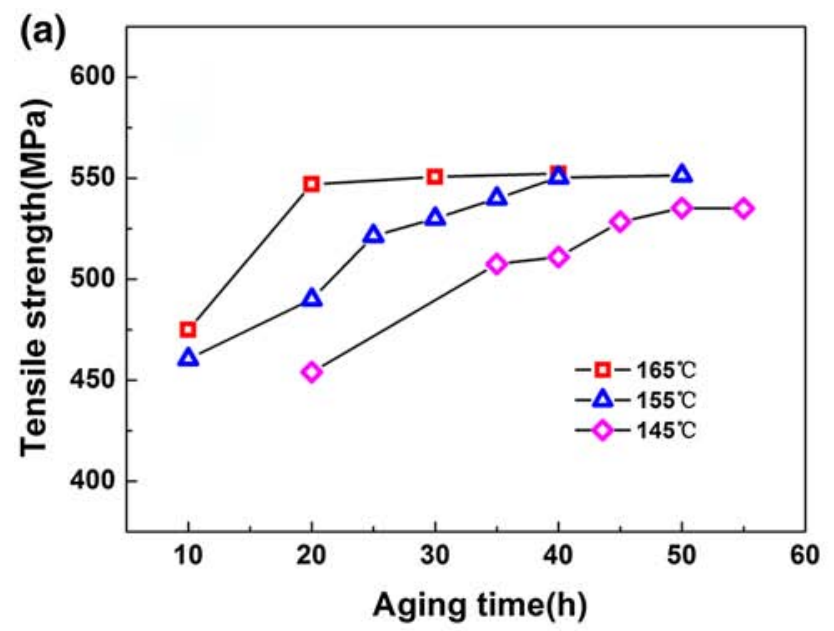

(c)

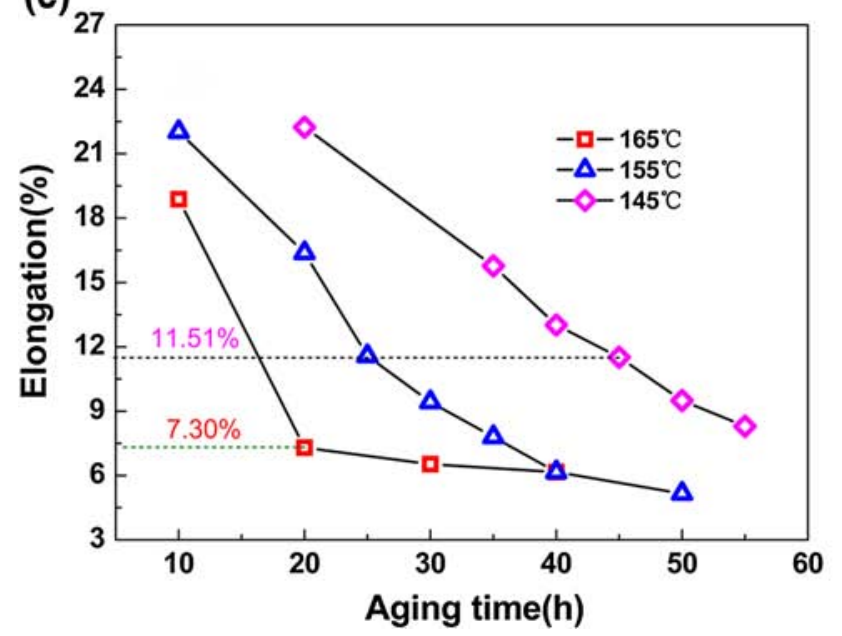

reveal that the aging response speeds up significantly at $165{ }^{\circ} \mathrm{C}$, and a higher strength and lower plasticity can be obtained in this condition. However, the plasticity is greatly improved when the aging temperature decreases to $145^{\circ} \mathrm{C}$, in spite of a slightly strength reduction.

Aircraft damage tolerance requires the most reasonable combinations of strength, plasticity, toughness as well as fatigue. The plasticity and toughness simply dominant the damage tolerance for a peak-aged aluminum alloy, as the strength fluctuates slightly in different peak-aging treatments. Therefore, a better plasticity is mostly preferred when the strength reaches a certain level (520-530 $\mathrm{MPa}$ for the investigated alloy). For this reason, the processing route of $145^{\circ} \mathrm{C} / 45 \mathrm{~h}$ or $155^{\circ} \mathrm{C} / 30 \mathrm{~h}$ is desirable for this novel aluminum-lithium alloy.

\subsection{Toughness}

Figure 3 shows the typical curve of the tear test. The crack initiates when the stress reaches the maximum, and after

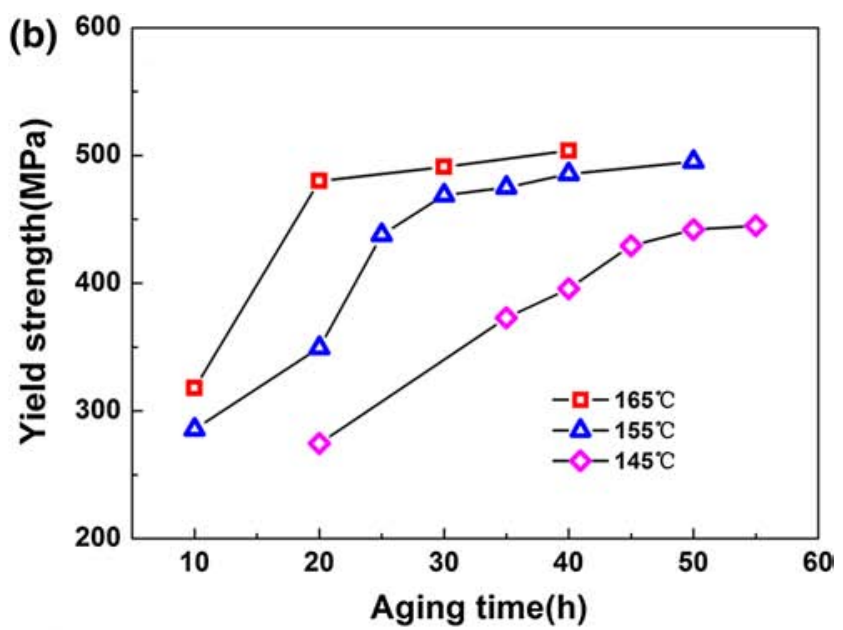

Fig. 2 The effect of the aging time on the tensile properties: a the tensile strength; $\mathbf{b}$ the yield strength; $\mathbf{c}$ the elongation 


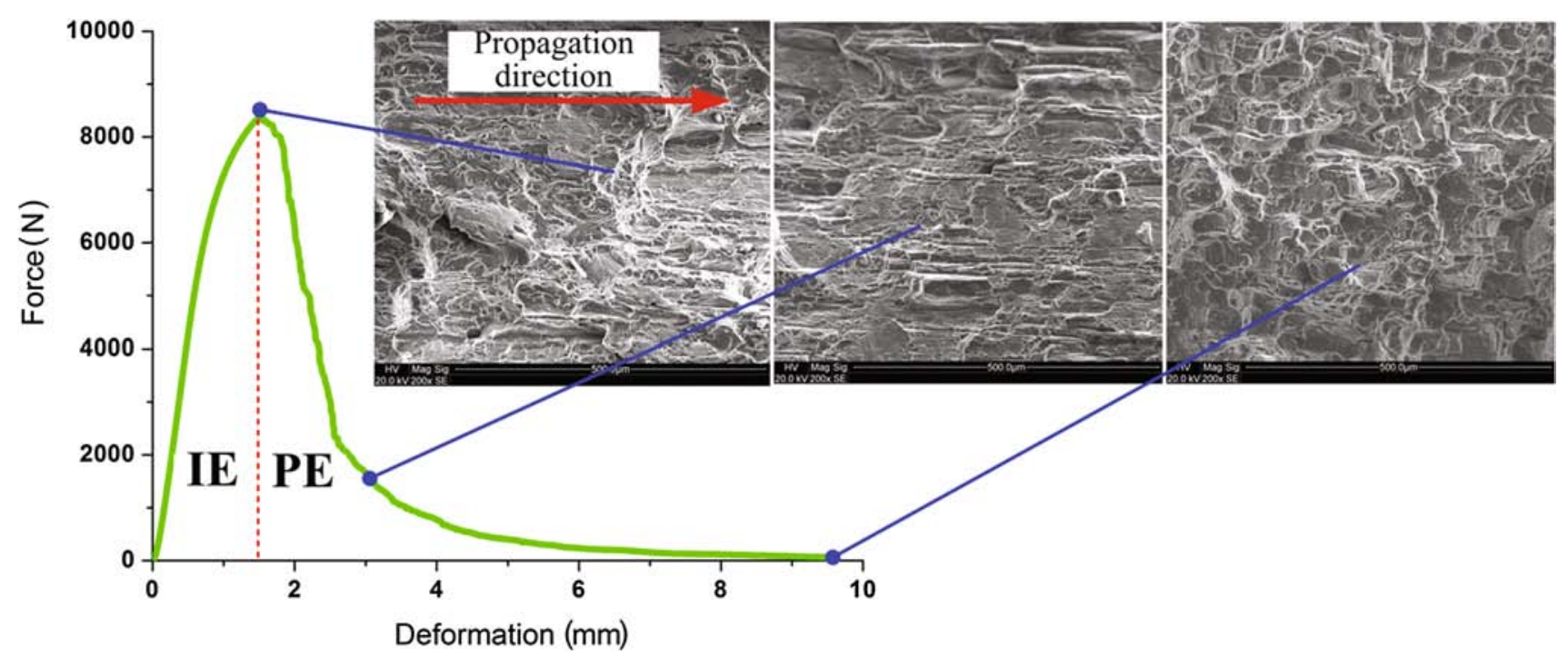

Fig. 3 Tear-test curve and the fracture morphology

that, the crack begin to expand. Hence, the area surrounded by test curve is divided into two parts: initiation energy $\left(E_{\mathrm{i}}\right)$ and propagation energy $\left(E_{\mathrm{p}}\right)$. The fracture morphology shows the three stages of the tear test: crack initiation, crack propagation and rupture failure, corresponding to the different regions of test curve in Fig. 3. The morphology of propagation region displays obvious tearing ridge, while great numbers of the dimples are observed in the rupture region because of the tensile stress applied in that stage.

The tear strength $\left(\sigma_{\mathrm{TS}}\right)$ is the maximum nominal tensile and bending stresses that the tear specimen is capable of sustaining. The $\sigma_{\mathrm{TS}}$ can be calculated according to the following equation $[20,21]$ :

$\sigma_{\mathrm{TS}}=\frac{P}{A}+\frac{M C}{I}=\frac{P}{b t}+\frac{3 P}{b t}=\frac{4 P}{b t}$,

where $P$ is the maximum force, $t$ is the average specimen thickness, $b$ is the distance between the notch root and the back edge of the specimen, $M$ is the bending moment, $C$ is the distance from neutral axis to outermost fiber, and $I$ is the moment of inertia.

The ratio of the tear strength to the material's yield strength, $R_{\mathrm{TY}}$, can be calculated simply by

$R_{\mathrm{TY}}=\frac{\sigma_{\mathrm{TS}}}{\sigma_{\mathrm{y}}}$,

where $\sigma_{\mathrm{y}}$ is yield strength.

Meanwhile, the calculation formula for ultimate propagation energy is shown below.

$E_{\mathrm{UP}}=\frac{E_{\mathrm{P}}}{b t}$.

In the Eq. (3), $E_{\mathrm{p}}$ is determined by integrating the area under the force displacement curve from the point of the maximum force to the point of complete fracture.
Both $E_{\mathrm{UP}}$ and $R_{\mathrm{TY}}$ values, treated as the measurement of toughness, were calculated and are listed in Table 2. It can be seen that the $E_{\mathrm{UP}}$ and $R_{\mathrm{TY}}$ values of the alloy aged at $155^{\circ} \mathrm{C}$ for $30 \mathrm{~h}$ or $145^{\circ} \mathrm{C}$ for $45 \mathrm{~h}$ are more desirable compared with those at $165^{\circ} \mathrm{C}$ for $20 \mathrm{~h}$. The morphology of the propagation region aged at different grades is shown in Fig. 4. Many dense dimples, together with the tearing ridge, are observed when aged at $145^{\circ} \mathrm{C}$ for $45 \mathrm{~h}$ (Fig. 4a). However, some transverse cracks appear, and the numbers of the dimples decrease after a treatment of $165^{\circ} \mathrm{C}$ for 20 h, shown in Fig. 4b, which indicates a deterioration of the toughness and the plasticity.

Overall, the $E_{\mathrm{UP}}$ and $R_{\mathrm{TY}}$ values indicate the similar changes of the toughness, which is also confirmed by the tearing morphology. These results demonstrate that the tear test is quite appropriate for the toughness evaluation of novel aluminum-lithium sheets.

\subsection{TEM Analysis}

The TEM images of the investigated alloy aged at $145{ }^{\circ} \mathrm{C}$ are shown in Figs. 5 and 6. The precipitates of some fine $T_{1}$ phases and $\delta^{\prime}$ phases are observed in the samples aged at $145^{\circ} \mathrm{C}$ for $35 \mathrm{~h}$ (Fig. 5a). Obviously, the extension of the aging time from $35 \mathrm{~h}$ to $45 \mathrm{~h}$ results in the more

Table 2 Calculated toughness of the aged alloy

\begin{tabular}{lcll}
\hline Aging process & $E_{\mathrm{UP}}(\mathrm{N} / \mathrm{mm})$ & $\sigma_{\mathrm{TS}}(\mathrm{MPa})$ & $R_{\mathrm{TY}}$ \\
\hline $165^{\circ} \mathrm{C} / 20 \mathrm{~h}$ & 40.83 & 681.60 & 1.42 \\
$155^{\circ} \mathrm{C} / 30 \mathrm{~h}$ & 63.98 & 679.76 & 1.45 \\
$145^{\circ} \mathrm{C} / 45 \mathrm{~h}$ & 102.65 & 631.17 & 1.47 \\
\hline
\end{tabular}



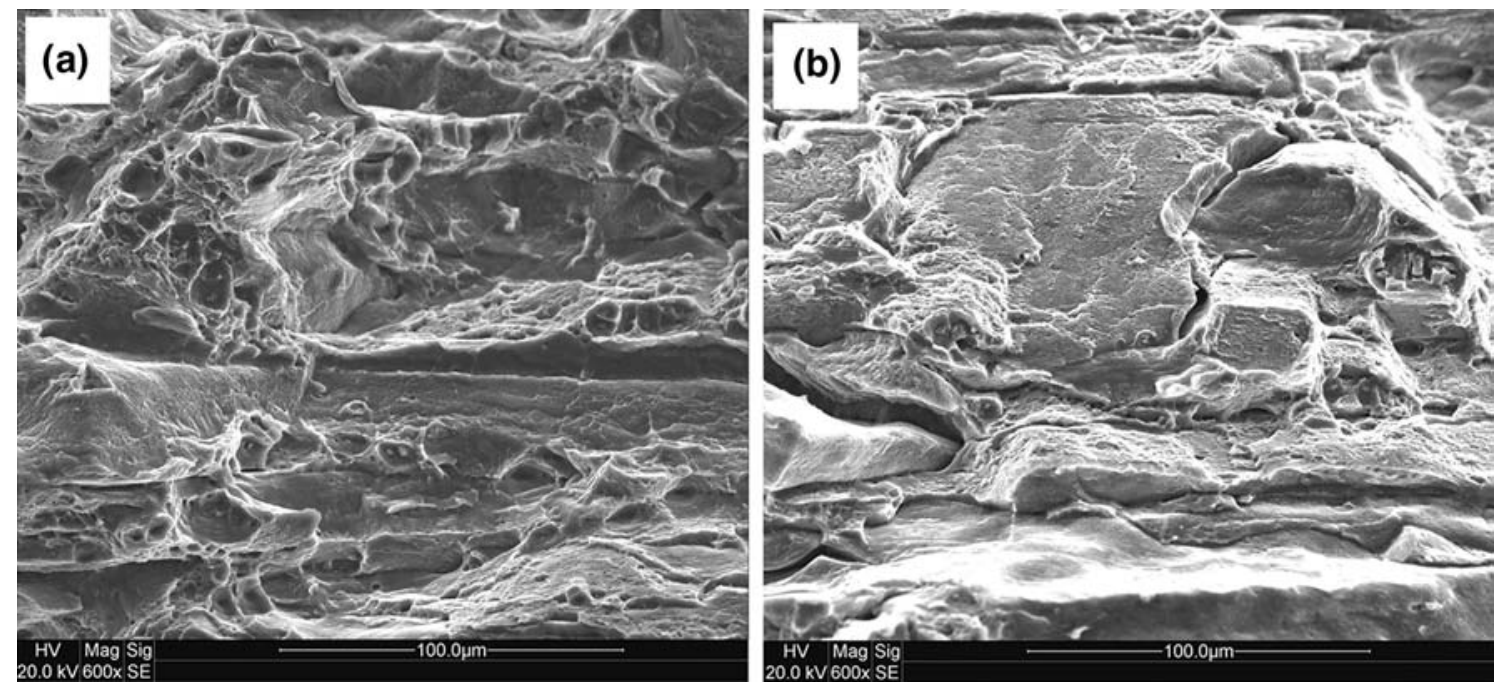

Fig. 4 The morphologies of the propagation region: a $145^{\circ} \mathrm{C}, 45 \mathrm{~h} ; \mathbf{b} 165^{\circ} \mathrm{C}, 20 \mathrm{~h}$
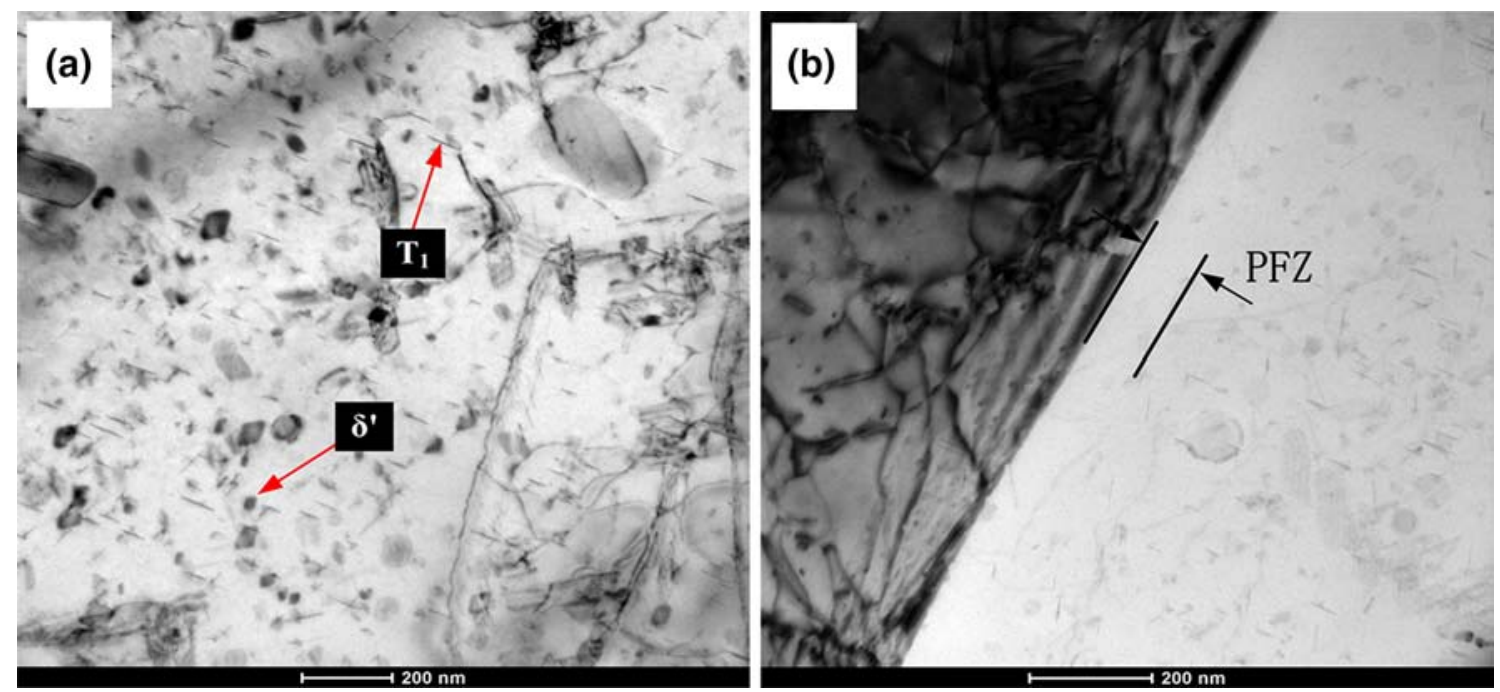

Fig. 5 TEM images of the novel aluminum-lithium alloy aged at $145{ }^{\circ} \mathrm{C}, 35 \mathrm{~h}$ : a the precipitated phases; b the PFZ

precipitation and rapider size growth of $\mathrm{T}_{1}$ phases (Fig. 6a), which also reduces the amount of $\delta^{\prime}$ phases. Among the phases of $\mathrm{Al}-\mathrm{Cu}-\mathrm{Li}$ alloy, $\delta^{\prime}$ phase can be easily cut by the dislocations in under-aged state, taking the spherical shape with a close lattice match $(a=0.4304$ $0.4308 \mathrm{~nm}$ for $\delta^{\prime}$, while for matrix, $a=0.404 \mathrm{~nm}$ ) [22]. Meanwhile, $\mathrm{T}_{1}$ plate is the primary strengthening phase in aged $\mathrm{Al}-\mathrm{Cu}-\mathrm{Li}$ alloys [23]. The hexagonal $\mathrm{T}_{1}\left(\mathrm{Al}_{2} \mathrm{CuLi}\right)$ phase with symmetry $\mathrm{p} 6 / \mathrm{mmm}$ forms as platelets on the $\{111\}$ planes of the $\mathrm{Al}$ matrix [24]. The $\mathrm{T}_{1}$ phase for the novel alloy is confirmed by the diffraction pattern (Fig. 6b), which shows the orientation relationship: $[\overline{1} 2 \overline{1} 3]_{\mathrm{T}_{1}} / /[110]_{\mathrm{Al}}$. Usually, $\mathrm{T}_{1}$ plates are extremely thin, $1.3 \mathrm{~nm}$ in thickness, which is equivalent to the stacking of only five $\{111\} \mathrm{Al}$ planes. These plates have a very large extension, up to $100 \mathrm{~nm}$, without losing their coherency with the matrix [25]. The precipitation features of $T_{1}$ phase dominate the mechanical properties [26]. For this reason, it is the precipitation and the growth of $\mathrm{T}_{1}$ leading to the significant increment in tensile strength and yield strength of the novel alloy. Besides, PFZ with $85 \mathrm{~nm}$ width emerges after aging for $35 \mathrm{~h}$ at $145{ }^{\circ} \mathrm{C}$, when a broadened width of $150 \mathrm{~nm}$ is observed when aging time up to $45 \mathrm{~h}$, as shown in Figs. 5b and 6c.

The TEM images of the investigated alloy aged at $165^{\circ} \mathrm{C}$ for $20 \mathrm{~h}$ are presented in Fig. $7 \mathrm{a}$ and b, which indicate a notable difference with the alloy aged at $145^{\circ} \mathrm{C}$ for $45 \mathrm{~h}$. The phase of $\delta^{\prime}$ still exists in the matrix, and an 

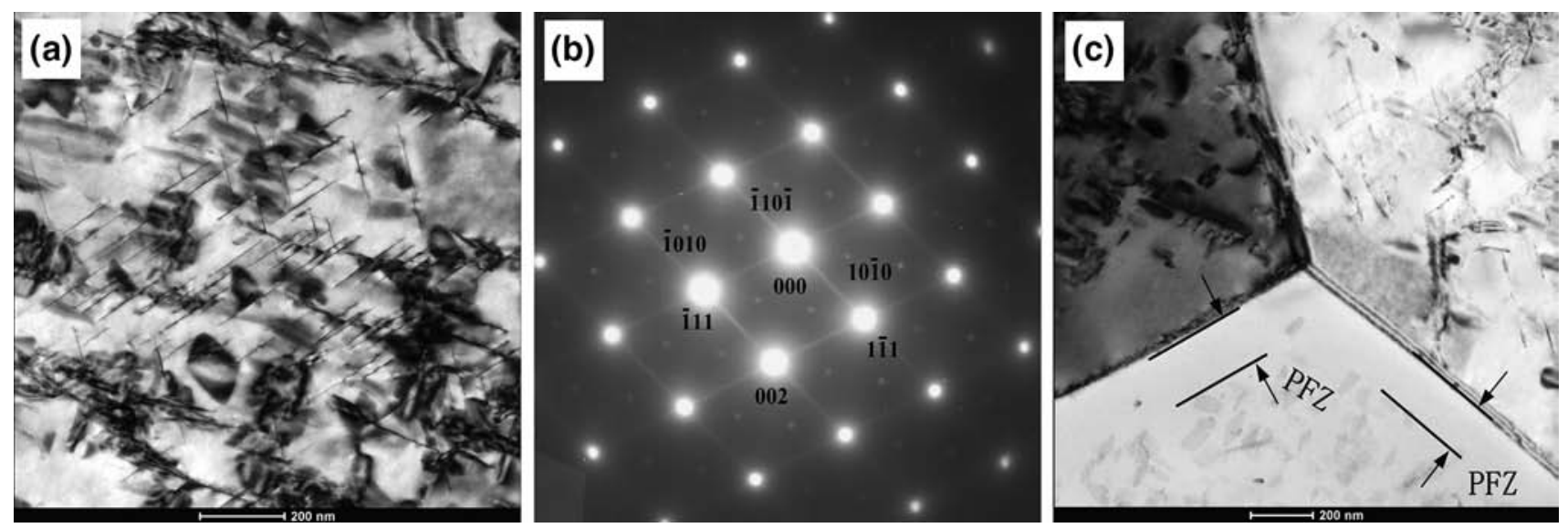

Fig. 6 TEM images of the novel aluminum-lithium alloy aged at $145{ }^{\circ} \mathrm{C}, 45 \mathrm{~h}$ : a the precipitated phases; $\mathbf{b}$ the corresponding diffraction pattern of $\mathrm{T}_{1} ; \mathbf{c}$ the PFZ
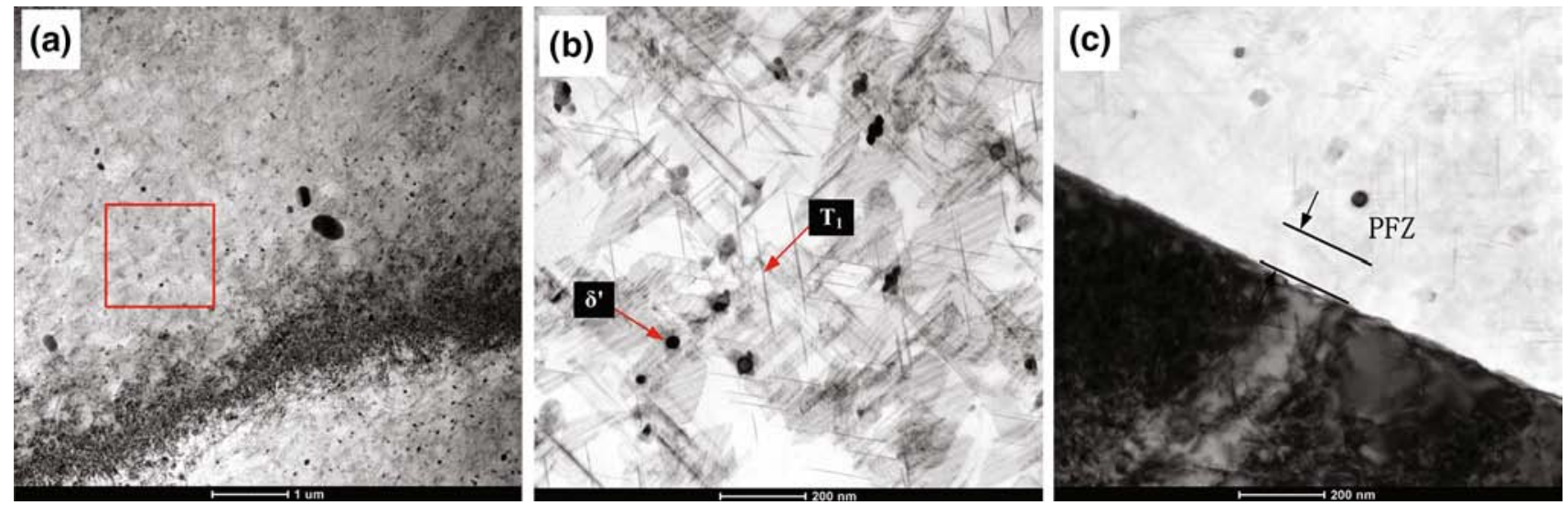

Fig. 7 TEM images of the novel aluminum-lithium alloy aged at $165^{\circ} \mathrm{C}, 20 \mathrm{~h}$ : a the precipitated phases; $\mathbf{b}$ the amplification image of selected area (a); $\mathbf{c}$ the PFZ

obvious size increment in $\mathrm{T}_{1}$ (diameter $>200 \mathrm{~nm}$ ) is observed. Moreover, the PFZ with a width of more than $100 \mathrm{~nm}$ occurs, shown in Fig. 7c. Hence, an obvious size growth of main precipitated phases may lead to the deterioration of plasticity and toughness at $165^{\circ} \mathrm{C}$ for $20 \mathrm{~h}$.

The mechanism of aging behavior for the novel aluminum-lithium alloy at different temperatures is discussed. When aged at $165^{\circ} \mathrm{C}$, oversaturated vacancies of postquenching alloy are provided with a high diffusion rate to move quickly to the grain boundaries and then annihilate. In this way, the density of oversaturated vacancies in the grain interior decreases, which is adverse for the formation of dislocation loops and vacancies, indicating a reduction in defect density [11,27]. Consequently, second phases are inclined to precipitate along the grain boundary, and inhomogeneous precipitation is obtained, leading to the deterioration in toughness and plasticity. In contrast, superior combinations of the strength and plasticity for the investigated alloy can be obtained when aged at $145^{\circ} \mathrm{C}$. Firstly, a high dislocation density in the grain interior provides an advantage for the intragranular nucleation, because a low diffusion rate of oversaturated vacancy at $145^{\circ} \mathrm{C}$ results in a tendency for vacancy clustering, which is beneficial for the formation of the dislocation loops. Secondly, the great driving force of phase transformation also offers a promotion for intragranular nucleation, owing to the high oversaturated concentrations at a low aging temperature.

In addition, the novel aluminum-lithium alloy exhibits some different precipitation features with other reported $\mathrm{Al}-\mathrm{Cu}-\mathrm{Li}$ alloys, although they have some similar precipitation roles during the artificial aging [4, 28]. Firstly, it experiences a shorter incubation time of $\mathrm{T}_{1}$ phase, and it exhibits a higher aging response rate, comparing with AA2198, AA2196 and other Al-Cu-Li alloy [10, 29]. Secondly, $T_{1}$ phase saturates with a diameter from 100 to $150 \mathrm{~nm}$ when the investigated alloy reaches the peak aging, which is $40-60 \mathrm{~nm}$ for the $\mathrm{Al}-\mathrm{Cu}-\mathrm{Li}$ alloys with a $\mathrm{Cu} / \mathrm{Li}$ ratio of 2-3 [11]. Finally, a broadened PFZ [23, 30] is 
observed in aged novel alloy, owing to the significant size growth of $\mathrm{T}_{1}$.

\section{Conclusions}

(1) The preferable combination of the strength and plasticity was achieved when aged at $145^{\circ} \mathrm{C}$ for $45 \mathrm{~h}$ or $155^{\circ} \mathrm{C}$ for $30 \mathrm{~h}$. When aged to the peak-aging state, the investigated alloy exhibited better plasticity and toughness if the temperature decreased from $165{ }^{\circ} \mathrm{C}$ to $145^{\circ} \mathrm{C}$, in spite of a slight strength reduction.

(2) The precipitation behavior of novel aluminum-lithium alloy was extremely sensitive to the aging parameters. The primary precipitation of $\mathrm{T}_{1}$ and $\delta^{\prime}$ occurs in the alloy at the pre-aging stage. During the aging process, $\delta^{\prime}$ gradually transformed to $\mathrm{T}_{1}$, accompanying the broadening of PFZ.

(3) Tear test was quite appropriate for the toughness evaluation of novel aluminum-lithium sheets. The ultimate propagation energy $\left(E_{\mathrm{UP}}\right)$ and the ratio of the tear strength to the yield strength $\left(R_{\mathrm{TY}}\right)$ exhibited the same tendency. The size of $\mathrm{T}_{1}$ phase had a great influence on the toughness of the novel alloy. An obvious deterioration of the toughness occurred when the diameter of $\mathrm{T}_{1}$ exceeded $200 \mathrm{~nm}$.

Acknowledgments The authors gratefully acknowledge the financial support of the Fund of National Engineering and Research Center for Commercial Aircraft Manufacturing (No. SAMC13-JS-15-032), Jiangsu Innovation Program for Graduate Education (No. KYLX0259), the Fundamental Research Funds for the Central Universities, the Foundation of Graduate Innovation Center in NUAA (No. kfjj20130220) and Opening Project of Jiangsu Key Laboratory of Advanced Structural Materials and Application Technology (No. ASMA201401).

\section{References}

[1] A. Łukaszek-Sołek, Acta Metall. Sin. (Engl. Lett.) 28, 22 (2015)

[2] E.M. Hekmat-ardakan, F. Elgallad, X.G. Ajersch, Chen. Mater. Sci. Eng. A 558, 76 (2012)

[3] Y. Lin, Z.Q. Zheng, H.F. Zhang, Y. Han, Trans. Nonferrous Met. Soc. China 23, 1728 (2013)
[4] N. Jiang, X. Gao, Z.Q. Zheng, Trans. Nonferrous Met. Soc. China 20, 740 (2010)

[5] J. Chen, Y. Madi, T.F. Morgeneyer, J. Besson, Comput. Mater. Sci. 50, 1365 (2011)

[6] W. Yang, M. Wang, X. Sheng, Q. Zhang, Z. Wang, Acta Metall. Sin. 46, 1481 (2010). (in Chinese)

[7] Z. Chen, K. Zhao, L. Fan, Mater. Sci. Eng. A 588, 59 (2013)

[8] R.K. Gupta, N. Nayan, H.A.G. Nagasirees, S.C. Sharma, Mater. Sci. Eng. A 420, 228 (2006)

[9] A.K. Khan, J.S. Robinson, J. Microsc. 232, 534 (2008)

[10] B. Deschamps, F.D. Decreus, T. Geuser, M. Dorin, Weyland. Acta Mater. 61, 4010 (2013)

[11] A. Decreus, F.D. Deschamps, P. Geuser, C. Donnadieu, M. Sigli, Weyland. Acta Mater. 61, 2207 (2013)

[12] F. Wei, J. Li, R. Hu, H. Kou, Chin. J. Aeronaut. 21, 565 (2008). (in Chinese)

[13] Z. Tian, L. Xu, Y. Peng, X. Zhang, R. Li, Acta Metall. Sin. 44, 91 (2008). (in Chinese)

[14] A.L. Ning, Z.Y. Liu, C. Feng, S. Zeng, Acta Metall. Sin. 42, 1253 (2006). (in Chinese)

[15] T. Ogura, S. Hirosawa, A. Cerezo, T. Sato, Acta Mater. 58, 2209 (2010)

[16] P. Lequeu, K.P. Smith, A. Danielou, J. Mater. Eng. Perform. 19, 841 (2010)

[17] H.F. Huang, S.L. Liu, Acta Metall. Sin. (Engl. Lett.) 12, 80 (1999)

[18] A. Heinz, C. Haszler, S. Keidel, R. Moldenhauer, W.S. Benedictus, Miller. Mater. Sci. Eng. A 280, 102 (2000)

[19] T.F. Morgeneyer, J. Besson, H. Proudhon, M.J. Starink, I. Sinclair, Acta Mater. 57, 3902 (2009)

[20] H. Khanbareh, X. Wu, S. Van Der Zwaag, J. Mater. Sci. 47, $6246(2012)$

[21] Y. Shi, F. Zhong, X. Li, S. Gong, L. Chen, Mater. Sci. Eng. A 465, 153 (2007)

[22] L.A.H. Terrones, S.N. Monteiro, Mater. Charact. 58, 156 (2007)

[23] M. Dwyer, L.Y. Weyland, B.C. Chang, Muddle. Appl. Phys. Lett. 98, 201909 (2011)

[24] J.F. Li, Z.Q. Zheng, W.D. Ren, W.J. Chen, X.S. Zhao, S.C. Li, Trans. Nonferrous Met. Soc. China 16, 1268 (2006)

[25] S. Ahmadi, H. Arabi, A. Shokuhfar, J. Alloys Compd. 484, 90 (2008)

[26] Y. Ma, X. Zhou, G.E. Thompson, T. Hashimoto, P. Thomson, M. Fowles, Mater. Chem. Phys. 126, 46 (2011)

[27] S. Pogatscher, H. Antrekowitsch, H. Leitner, D. Poschmann, Z.L. Zhang, P.J. Uggowitzer, Acta Mater. 60, 4496 (2012)

[28] P. Donnadieu, Y. Shao, F. De Geuser, G.A. Botton, S. Lazar, M. Cheynet, M. De Boissieu, A. Deschamps, Acta Mater. 59, 462 (2011)

[29] H. Li, Y. Tang, Z. Zeng, Z. Zheng, F. Zheng, Mater. Sci. Eng. A 498, 314 (2008)

[30] Y. Lin, Z. Zheng, S. Li, X. Kong, Y. Han, Mater. Charact. 84, 88 (2013) 